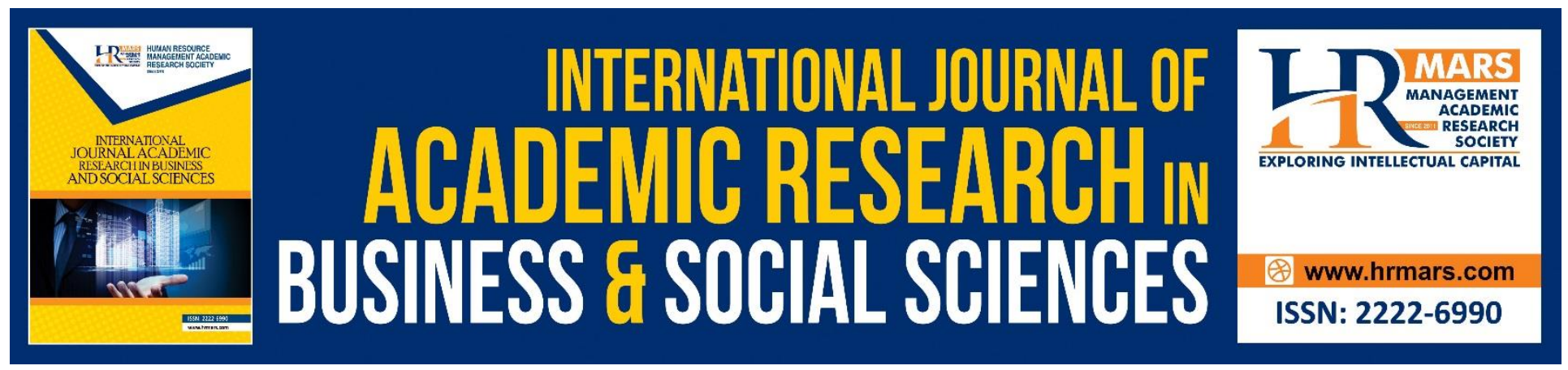

\title{
Insights on the Effectiveness of Library Benchmarking Adoption among Academic Libraries
}

Mohd Razilan Abdul Kadir, Nor Aliah Abdullah, Norhayati Hussin

To Link this Article: http://dx.doi.org/10.6007/IJARBSS/v8-i9/4592

DOI: $\quad 10.6007 /$ IJARBSS/v8-i9/4592

Received: 29 July 2018, Revised: 21 August 2018, Accepted: 25 Sept 2018

Published Online: 13 October 2018

In-Text Citation: (Kadir, Abdullah, \& Hussin, 2018)

To Cite this Article: Kadir, M. R. A., Abdullah, N. A., \& Hussin, N. (2018). Insights on the Effectiveness of Library Benchmarking Adoption among Academic Libraries. International Journal of Academic Research in Business and Social Sciences, 8(9), 298-313.

Copyright: (c) 2018 The Author(s)

Published by Human Resource Management Academic Research Society (www.hrmars.com)

This article is published under the Creative Commons Attribution (CC BY 4.0) license. Anyone may reproduce, distribute, translate and create derivative works of this article (for both commercial and non-commercial purposes), subject to full attribution to the original publication and authors. The full terms of this license may be seen at: $\underline{\text { http://creativecommons.org/licences/by/4.0/legalcode }}$

Vol. 8, No. 9, September 2018, Pg. 298 - 313

Full Terms \& Conditions of access and use can be found at http://hrmars.com/index.php/pages/detail/publication-ethics 


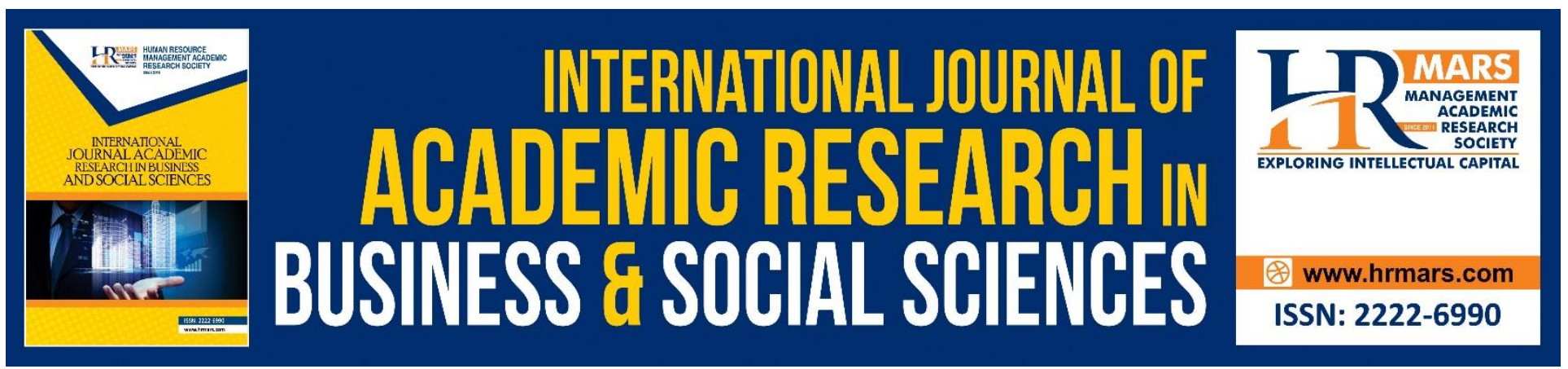

\title{
Insights on the Effectiveness of Library Benchmarking Adoption among Academic Libraries
}

\author{
Mohd Razilan Abdul Kadir, Nor Aliah Abdullah, Norhayati Hussin \\ Faculty of Information Management, Universiti Teknologi MARA, Puncak Perdana Campus, UiTM \\ Selangor, Shah Alam, Selangor, Malaysia. \\ Email:mrazilan@salam.uitm.edu.my,nraliahabdullah@gmail.com
}

\begin{abstract}
Library is one of the information centers that provides information services to its users. Throughout the rapid changing in technologies, the library also gets affected from it where their collections, services, facilities, interior design and others components need to improvise to meet the user needs and attract users to come to the library. The effectiveness of the library benchmarking adoption, as improvement tool, in academic library of public universities in Klang Valley, Malaysia is studied in this paper. Benchmarking measurement tool however has been widely implemented in some developing countries but its adoption is not widely applied in Malaysia. Hence this study attempts to identify the effectiveness of the library benchmarking adoption based on Malaysia's library eco-system. Survey method is opted where a set of questionnaire was distributed to six (6) academic library in public universities in Klang Valley, Malaysia comprises of a total of 142 randomly selected respondents (from the academic librarians). The findings of the study indicated that top management commitment, internal assessment, employee participation, the role of quality department, and customer orientation are positively correlated with effectiveness of library benchmarking adoption. However, benchmarking limitation was not significantly correlated with the effectiveness of the library benchmarking adoption.
\end{abstract}

Keywords: Academic Library, Benchmarking, Benchmarking Adoption, Library Benchmarking, Measurement Tools

\section{Introduction}

Library is one of the information centers that provides information services to its users. Throughout the rapid changing in technologies, the library also gets affected from it where their collections, services, facilities, interior design and others components need to improvise to meet the user needs and attract users to come to the library. Commonly, traditional library services been provided in-house while in $21^{\text {st }}$ century era, the services have changed from physical interaction to virtual interaction.

Most of these academic libraries have established for more than 30 years in providing the information services. To change from traditional to modern technology based services might take a 
INTERNATIONAL JOURNAL OF ACADEMIC RESEARCH IN BUSINESS AND SOCIAL SCIENCES Vol. 8, No. 9, Sept. 2018, E-ISSN: 2222-6990 @ 2018 HRMARS

lot of things to be considered and the performance of the library might be affected as well (Madhusudhan and Nagabhushanam, 2012). In order to measure the library performance, benchmarking is one of the effective measuring tools to be used that improves the library performance (Yean, Suhaiza and Keng, 2006). The study details the findings of the effectiveness of the library benchmarking among academic library in public universities in Klang Valley, Malaysia as their measurement tools.

Library is also one of the information centers that provide relevant and reliable information in a variety of materials to the users. In this 21st century era of technology, nature of the library has changed from traditional to the modern library where the services not only focus on the core business such as provides physical materials but also build up the electronic resources, online communication paradigms, and others along with the role of the librarians (Madhusudhan and Nagabhushanam, 2012). John Abdul Kargbo (2008) stated that role of the librarians also need to be re-orientate in order to fulfill user needs either in-house or in electronic based.

This study focuses on the effectiveness of the library benchmarking adoption at an academic library in public universities in Klang Valley, Malaysia. The study is important to the libraries as it capable of helping to identify the strength and weaknesses of the organizations and as well to perform better in the future. The study is also expected to support libraries in terms of provisioning the best services as an information center in their universities and consistently evaluating their performance. Overall, the findings can be used as a guideline to academic libraries to improve their organizations' service and to improve users' experience via the services provided.

\section{Review of the Previous Literature}

Benchmarking is one of the best practices in order to improve the performance or the organization. He also added that benchmarking focus on compare the future performance and analyzing forward-looking. Benchmarking also can be defined as a structured process where the process had been developing in step by step process and give common guideline (Spendolini, 1992). Sarkins (2001) stated that benchmarking has been defined as ongoing, systematic process of evaluating the services or certain fields that they want to benchmark.

Zairi and Ahmed (1999) said that benchmarking adoption commonly hard to be implemented because it needs major changes in the organizations. This is because the changes of the benchmarking consist of analysis and comparison through strategies, functions, processes, product or services, performance, etc. of the organizations to improve the performance (Anand and Kodali, 2008). Implementation of benchmarking has been used in a variety of fields or industry and one of it is higher education. Unfortunately, not all higher education knows well the concept of the benchmarking itself and leads to ineffective results (Meek and van der Lee, 2005). Benchmarking was defined as an exploration of new ways to manage the institution more efficient by using new approach (Elder and Massam, 2016). In other ways benchmarking play a role to continually improve and stayed reasonable in the industry (Tasopoulou and Tsiotras, 2017). They also said that benchmarking is one of the instrument that successful for assessment and improvement in the organizations as long as the top management give the commitment in implemented it.

In 1997, Malaysian Benchmarking Services (MBS) had been set up by National Productivity Corporation (NPC) to provide training and expertise and be the reference center in providing the information of the benchmarking (Lee, Suhaiza, and Soh, 2006). This organization can be used by the library in order to get a better vision of benchmarking adoption as their performance evaluation. This would be very helpful to the library in implementing the benchmarking process in effective and 
efficient continuous ways (Elmuti and Kathawala, 1997). In other perspective, benchmarking adoption is made by learning from other organizations that had been selected to benchmark. This is one of the easy ways to benchmark where the library improvement is started by comparing and measuring the processes, tools, and techniques. Through this way, the library can build up the networking with other library in order to collaborate for better practice, performance and provide a guideline to improved (Jackson, 2001). The library can do benchmarking activities by selecting several activities or fields to be used in analyzing with the other libraries (Schofield, 1998). In other words, the library performs a comparison of performance and process which similar to each other to get a better understanding of evaluation of the performance (Simon and Howard, 2014).

The followings provide some elaborations on six dimensions of construct posited to influence the effectiveness of library benchmarking adoption.

\section{Top Management Commitment}

Top management commitment is the major factor for benchmarking adoption where they are the one that making sure the successfulness of the application (Chen, 1997; Thiagarajan and Zairi, 1998; Agus, 2001; Sureshchandar et al., 2001; Sharma and Gadenne, 2001; Antony et al., 2002; Sohail and Teo, 2003; Lee et al., 2006). In addition, top management is the one who approves the implemention of benchmarking and their support is very much important (Fong, Shen and Cheng, 2001).

\section{Internal Assessment}

For internal assessment, it focuses on the evaluation of culture, training, and communication in the organizational itself (Lee et al., 2006). Furthermore, the contribution of internal assessment gives high benefits towards benchmarking adoption (Brah et al., 2000). Internal assessment is important in recognizing the current library performance and its quality in order to achieve the objectives and goals (Dale, 1996; Jones, 2000; Lee et al., 2004). Besides that, through internal assessment, it would lead to a better understanding of their operations of the organization before they get the benefits from benchmarking adoption (Sweeney, 1994; Brah et al., 2000; Lee et al., 2004).

\section{Employee Participation}

Employee participation in this study related to the commitment of employee in gaining a better performance in benchmarking adoption (Arthur, 1994; Lee et al., 2006). Benchmarking adoption needs continuous improvement not only the management, services but also the employee performance this leads to improvement of the productivity of the employee itself (Cooke, 1994; Daniels and Burns, 1997; Pun et al., 2001).

\section{Benchmarking limitation}

For benchmarking limitation, it relates to the lack of understanding of the benchmarking concept which leads to poor results (Brah et al., 2000; Lee et al., 2006). This eventually leads to confusion on the usefulness of the technique and doubt rises (Adebanjo et al. 2010).

\section{Role of Quality Department}

The role of quality department commonly relates to performance evaluation of specific services or products. This department supposed to play a vital role in managing the measurement technique in order to ensure the organization gets the benefits of it (Lee et al., 2006). The quality department has 
INTERNATIONAL JOURNAL OF ACADEMIC RESEARCH IN BUSINESS AND SOCIAL SCIENCES

Vol. 8, No. 9, Sept. 2018, E-ISSN: 2222-6990 @ 2018 HRMARS

been defined as one of the major factors of the effectiveness for benchmarking adoption (Antony et al., 2002).

\section{Customer Orientation}

Basically, customer orientation focuses on the level of customer satisfaction that can be found in benchmarking adoption. Agus et al. (2000) claimed that customer satisfaction could be enhanced by the benchmarking adoption and will improve the organization performance.

The proposed study theoretical framework is as given in Figure 1.

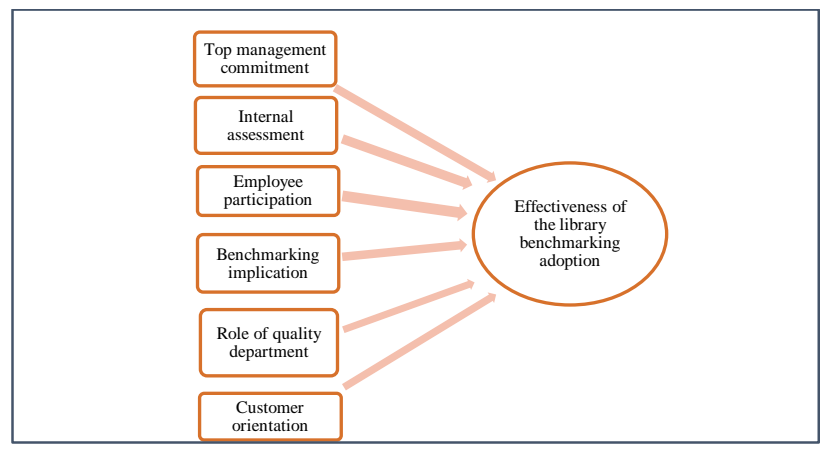

Figure 1. Theoretical framework

Based on the study framework as given in Figure 1, the following hypotheses are drawn:

H1: Benchmarking effectiveness is influenced by the top management.

H2: Benchmarking effectiveness is influenced by the internal assessment of the library.

H3: Benchmarking effectiveness is influenced by the employee participation.

H4: Benchmarking effectiveness is influenced by the benchmarking limitation.

H5: Benchmarking effectiveness is influenced by the role of the quality department.

H6: Benchmarking effectiveness is influenced by the customer orientation of the library.

\section{Research Methodology}

\section{Data Collection}

This study opts quantitative method research via survey. Quantitative method research is a type of method that explaining the study by collecting numerical data based on survey instrument selected. This approach uses a structured questionnaire designated to collect data from the respondent of this study where the questionnaires are distributed manually by hand.

\section{Population and Sample}

The population of this study comprises of all academic library in public universities in Klang Valley, Malaysia which consist of six (6) universities. The analysis sample targeted in this study is 142 
INTERNATIONAL JOURNAL OF ACADEMIC RESEARCH IN BUSINESS AND SOCIAL SCIENCES Vol. 8, No. 9, Sept. 2018, E-ISSN: 2222-6990 @ 2018 HRMARS

respondents. The respondents for this study are targeted to be librarian or top management of the library in the academic libraries as they are expected to have the knowledge and as well authority towards library benchmarking adoption. Raosoft software is used to assist researcher in estimating the appropriate total number of sample size for the study. Raosoft provides sample size calculator that can be used to calculate the sample size of the respondent from a total population of this study. This calculator consists of an acceptable margin of error, confidence level, response distribution and size of the defined population proposed for this study. Following the conventional use, the margin of error applied is $5 \%$ and with a confidence level of $90 \%$. Thus, the total sample size needed for this study is 142 respondents, as being reckoned by Raosoft sample size calculator application.

\section{Variables and Measurement}

Top management commitment is measured by five elements for i) quality improvement, ii) understand the improvement objectives and benefits, iii) takes action towards executing the quality improvement policies, iv) willing to commit time and resources to improve, and v) consideration in integrate quality improvement into strategic planning.

Internal assessment is measured by seven elements: i) openness of employees towards changes, ii) truly know and understand their own operations, iii) awareness of learning portfolio in the organization, iv) culture difficulties, v) understanding of benchmarking method, vi) good communication among employees, and vii) quality training availability.

Employee participation is measured by three elements: i) employee understanding of the project's objectives and benefits, ii) commitment to quality improvement, and iii) availability of the system for employees to suggest improvement.

Benchmarking limitation is measured by five elements: i) the organization perceive that benchmarking is too costly, ii) too time-consuming, iii) difficult to identify benchmarking partners, iv) difficult to obtain useful information about competitors, and v) difficult to quantify areas that involve skills.

The role of the quality department is measured by six elements: i) the ability to access to top management, ii) its autonomy to run any project regarding quality improvement, iii) utilization of its quality staff professionals, iv) the effectiveness of improving quality, v) comprehensiveness of the quality program, and vi) visibility of the quality department in the company.

Customer orientation is measured by five elements: i) the organization commitment to the customer, ii) comparing customer satisfaction with competitors and internal indicators, iii) development of strategies for customer satisfaction; iv) utilizing customer satisfaction as part of their performance, and $\mathrm{v}$ ) responsiveness to a customer complaint.

\section{Analysis and Findings}

All of the data gathered from the survey opted in the study is analysed using SPSS version 20, a statistical tool to analyze the quantitative data that is widely used in social science. SPSS is one of the powerful analytic tools that employs technique and statistical features to assist researchers in extracting findings of the data analytics There are several steps of analyses performed in this study 
INTERNATIONAL JOURNAL OF ACADEMIC RESEARCH IN BUSINESS AND SOCIAL SCIENCES

Vol. 8, No. 9, Sept. 2018, E-ISSN: 2222-6990 (C) 2018 HRMARS

i.e. Factor analysis for data reduction purpose which includes Common Method Bias, reliability analysis, frequency analysis, descriptive analysis, and correlation analysis.

\section{Common Method Bias (CMB)}

$\mathrm{CMB}$ is a measurement error ( $r$ (Podsakoff, MacKenzie, Lee, \& Podsakoff, 2003; Podsakoff, MacKenzie, \& Podsakoff, 2012)) and is a condition where there are variations of response from the respondent which caused by the instrument rather than what the respondent's answer in the survey. In other words, the instrument caused a bias in research where the responses may not portray the actual situation due to the biasedness. Consequently, the results will be contaminated by the 'noise' stemming from the biased instruments. The statistical approaches also play another objective role to control for the common method bias influence. Statistical controls against the common method bias used in the study is via Harman's single factor test. The results from the test as given in Table 1 show that the single factor explained only $33.3 \%$ of the total variance $(<50 \%$ as suggested by Podsakoff et al., 2003), hence suggesting that the collected data is free from the threats of common methods bias. In other words, the study instrument is free from significant common method bias effects. 
INTERNATIONAL JOURNAL OF ACADEMIC RESEARCH IN BUSINESS AND SOCIAL SCIENCES Vol. 8, No. 9, Sept. 2018, E-ISSN: 2222-6990 @ 2018 HRMARS

Table 1: Total variance explained of the research response as extracted using running unrotated, a single factor constraint of factor analysis

\begin{tabular}{|c|c|c|c|c|c|c|c|}
\hline \multirow{3}{*}{$\begin{array}{c}\text { Componen } \\
\mathrm{t}\end{array}$} & \multicolumn{3}{|c|}{ Initial Eigenvalues } & \multicolumn{3}{|c|}{$\begin{array}{c}\text { Extraction Sums of Squared } \\
\text { Loadings }\end{array}$} & \\
\hline & & $\%$ of & Cumulative & & $\%$ of & Cumulative & \\
\hline & Total & Variance & $\%$ & Total & variance & $\%$ & \\
\hline 1 & 13.250 & 33.126 & 33.126 & 13.250 & $3 \overline{3} \cdot \overline{12}$ & $\sqrt{33.126}$ & snows \\
\hline 2 & 3.949 & 9.873 & 42.999 & & & varia & iance \\
\hline 3 & 3.541 & 8.854 & 51.852 & & & explain & ned by a \\
\hline 4 & 2.512 & 6.281 & 58.133 & & & single & factor \\
\hline 5 & 1.819 & 4.547 & 62.681 & & & indicat & ates the \\
\hline 6 & 1.787 & 4.467 & 67.148 & & & common & method \\
\hline 7 & 1.271 & 3.178 & 70.326 & & & bias 1\$ & 1s not a \\
\hline 8 & 1.066 & 2.666 & 72.992 & & & this & study \\
\hline 9 & 1.011 & 2.526 & 75.518 & & & & \\
\hline 10 & .868 & 2.171 & 77.689 & & & & \\
\hline 11 & .717 & 1.793 & 79.482 & & & & \\
\hline 12 & .665 & 1.663 & 81.145 & & & & \\
\hline 13 & .590 & 1.474 & 82.619 & & & & \\
\hline 14 & .568 & 1.419 & 84.037 & & & & \\
\hline 15 & .516 & 1.290 & 85.328 & & & & \\
\hline 16 & .480 & 1.200 & 86.527 & & & & \\
\hline 17 & .450 & 1.126 & 87.653 & & & & \\
\hline 18 & .420 & 1.050 & 88.703 & & & & \\
\hline 19 & .395 & .988 & 89.691 & & & & \\
\hline 20 & .347 & .869 & 90.559 & & & & \\
\hline 21 & .341 & .854 & 91.413 & & & & \\
\hline 22 & .323 & .807 & 92.220 & & & & \\
\hline 23 & .308 & .770 & 92.989 & & & & \\
\hline 24 & .271 & .678 & 93.667 & & & & \\
\hline 25 & .264 & .660 & 94.327 & & & & \\
\hline 26 & .249 & .623 & 94.950 & & & & \\
\hline 27 & .240 & .601 & 95.550 & & & & \\
\hline 28 & .223 & .558 & 96.108 & & & & \\
\hline 29 & .208 & .521 & 96.629 & & & & \\
\hline 30 & .193 & .482 & 97.111 & & & & \\
\hline 31 & .177 & .442 & 97.552 & & & & \\
\hline 32 & .169 & .424 & 97.976 & & & & \\
\hline 33 & .150 & .376 & 98.352 & & & & \\
\hline 34 & .134 & .334 & 98.686 & & & & \\
\hline 35 & .118 & .296 & 98.982 & & & & \\
\hline 36 & .109 & .271 & 99.254 & & & & \\
\hline 37 & .091 & .228 & 99.481 & & & & \\
\hline 38 & .086 & .215 & 99.696 & & & & \\
\hline 39 & .064 & .159 & 99.855 & & & & \\
\hline 40 & .058 & .145 & 100.000 & & & & \\
\hline
\end{tabular}


INTERNATIONAL JOURNAL OF ACADEMIC RESEARCH IN BUSINESS AND SOCIAL SCIENCES Vol. 8, No. 9, Sept. 2018, E-ISSN: 2222-6990 @ 2018 HRMARS

\section{Reliability}

Reliability was checked based on Cronbach's alpha value. It is a test of the ability of measure to produce consistent results when the same entities are measured under different conditions (Hair et al., 2006). As indicated by Sekaran (2003), the Cronbach's alpha coefficient is ranging $0.0<\alpha<1.0$ and $\alpha<0.6$ is considered to be poor. In Table 2 , the reliability test results are all $>0.80$, which indicates good internal consistency reliability. For the effectiveness of library benchmarking adoption, the $\alpha=0.927$, which shows high internal consistency reliability.

Table 2: Reliability results of internal consistency of the scales used in the survey

\begin{tabular}{|l|c|c|}
\hline \multicolumn{1}{|c|}{ Construct } & $\begin{array}{c}\text { Total } \\
\text { Items }\end{array}$ & $\begin{array}{c}\text { Cronbach's } \\
\text { Alpha }\end{array}$ \\
\hline $\begin{array}{l}\text { Top management } \\
\text { commitment }\end{array}$ & 5 & 0.937 \\
\hline Internal assessment & 8 & 0.882 \\
\hline Employee participation & 3 & 0.866 \\
\hline Benchmarking limitation & 5 & 0.896 \\
\hline Role of quality department & 7 & 0.895 \\
\hline Customer orientation & 5 & 0.872 \\
\hline $\begin{array}{l}\text { Effectiveness of library } \\
\text { benchmarking }\end{array}$ & 6 & 0.927 \\
\hline
\end{tabular}

\section{Factor Analysis}

Factor analysis was conducted to reduce the number of variables and detect structure in the relationship between variables. For the test, the dependent variable will be tested as it is the only question that meets the requirements for the test. Factor analysis was applied to 39-item scale designed to measure the effectiveness of library benchmarking adoption (1=Strongly Disagree 2=Disagree 3=Neutral 4=Agree 5=Strongly Agree). In order to ensure the data are correlated, KMO and Bartlett's Test of Sphericity is conducted and the results as displayed in Table 3. The test variable is inter-correlated which indicated by KMO index of .870 which shows that the data is suitable. Meanwhile, Bartlett's Test of Sphericity result indicates the significance of $p<0.05$. The minimum acceptable value for commonalities was set at 0.5. Whereas in Table 4, the commonalities of the data are shown in such way that the values $>0.5$ indicates that the variables have a lot in common with the other variables taken as a group.

Table 3: KMO and Bartlett's Test

\begin{tabular}{|l|l|l|}
\hline \multicolumn{2}{|l|}{$\begin{array}{l}\text { Kaiser-Meyer-Olkin } \\
\text { Adequacy. }\end{array}$} & 0.870 \\
\hline \multirow{3}{*}{$\begin{array}{l}\text { Bartlett's Test of } \\
\text { Sphericity }\end{array}$} & Approx. Chi-Square & 3566.34 \\
\cline { 2 - 3 } & Df & 3 \\
\cline { 2 - 3 } & Sig. & 0.000 \\
\hline
\end{tabular}


INTERNATIONAL JOURNAL OF ACADEMIC RESEARCH IN BUSINESS AND SOCIAL SCIENCES Vol. 8, No. 9, Sept. 2018, E-ISSN: 2222-6990 (C) 2018 HRMARS

Table 4: Rotated Component Matrix

\begin{tabular}{|l|c|c|}
\hline \multicolumn{1}{|c|}{ Items } & Initial & Extraction \\
\hline Top management dedicated to quality improvement & .821 & .711 \\
\hline Top management understand the improvement objectives & .867 & .840 \\
\hline $\begin{array}{l}\text { Top management takes action towards the quality } \\
\text { mprovement policies }\end{array}$ & .862 & .785 \\
\hline Top management willing to commit time to improve & .886 & .837 \\
\hline $\begin{array}{l}\text { Top management consider the quality intergration } \\
\text { improvement into strategic planning }\end{array}$ & .740 & .687 \\
\hline Openness of employee towards changes & .648 & .553 \\
\hline Truly know and understand the operations of the library & .697 & .575 \\
\hline Awareness of learning portfolio in the organization & .669 & .615 \\
\hline culture difficulties & .486 & .497 \\
\hline understanding of benchmarking method & .680 & .708 \\
\hline good communications among employee & .761 & .685 \\
\hline quality training availability & .705 & .605 \\
\hline Openness of employee towards new ideas & .710 & .662 \\
\hline Understanding of the benchmarking's objectives & .713 & .759 \\
\hline Commitment to quality improvement & .742 & .794 \\
\hline Availability of system for employees to suggest improvement & .656 & .599 \\
\hline Benchmarking is too costly & .708 & .552 \\
\hline too time consuming & .777 & .664 \\
\hline Difficult to identify benchmarking partners & .699 & .688 \\
\hline difficult to obtain useful information about competitors & .789 & .762 \\
\hline Difficult to quantity areas that involves skills & .766 & .675 \\
\hline Ability to access to top management & .641 & .533 \\
\hline Autonomy to run any project for quality improvement & .672 & .546 \\
\hline Utilization of its quality staff professionals & .719 & .747 \\
\hline Effectiveness of improving quality & .723 & .696 \\
\hline Comprehensiveness of the quality program & .712 & .698 \\
\hline Visibility of the quality department & .722 & .682 \\
\hline Effectiveness of boost awareness of their employees & .551 & .480 \\
\hline Commitment to customer & .538 & .524 \\
\hline Comparing customer satisfaction with competitors & .677 & .634 \\
\hline Development of strategies for customer satisfaction & .722 & .719 \\
\hline utilizing customer satisfaction as part of the performance & .715 & .744 \\
\hline Responsiveness to customer complaint & .650 & .642 \\
\hline
\end{tabular}

\section{Distribution of demographic profiles}

Frequency analysis was conducted for extracting the distribution of respondents' demographic profile of this study. Since this research is conducted for librarians of public University, it is clearly seen that majority of the librarian's age is more than 30 years (72.5\%) as shown in the Table 5 , but the least is shown by the respondent age of $21-25$ years (4.2\%). In terms of respondent's institution, the majority of the respondent tabulated for the study comes from Universiti Teknologi MARA (UiTM) with $23.9 \%$ while the least is from Universiti Pertahanan Nasional Malaysia (UPNM) with $12.7 \%$. Moreover, the result is also showing that more than $80 \%$ of the respondents are having working experience of 10 years and below. 
INTERNATIONAL JOURNAL OF ACADEMIC RESEARCH IN BUSINESS AND SOCIAL SCIENCES Vol. 8, No. 9, Sept. 2018, E-ISSN: 2222-6990 @ 2018 HRMARS

Table 5: Distribution of respondent's demographic profiles

\begin{tabular}{|c|c|c|c|}
\hline Profiles & Category & Frequency & $\%$ \\
\hline \multirow{3}{*}{ Age } & $21-25$ years old & 6 & 4.2 \\
\hline & $26-30$ years old & 33 & 23.2 \\
\hline & More than 30 years old & 103 & 72.5 \\
\hline \multirow{6}{*}{ University } & University of Malaya & 23 & 16.2 \\
\hline & University Putra Malaysia & 26 & 18.3 \\
\hline & $\begin{array}{l}\text { National University of } \\
\text { Malaysia }\end{array}$ & 18 & 12.7 \\
\hline & $\begin{array}{l}\text { International Islamic } \\
\text { University Malaysia }\end{array}$ & 33 & 23.2 \\
\hline & Universiti Teknologi MARA & 34 & 23.9 \\
\hline & $\begin{array}{l}\text { Universiti Pertahanan Nasional } \\
\text { Malaysia }\end{array}$ & 8 & 5.6 \\
\hline \multirow{5}{*}{$\begin{array}{l}\text { Years of } \\
\text { working }\end{array}$} & 5 years and less & 71 & 50 \\
\hline & 6 to 10 years & 50 & 35.2 \\
\hline & 11 to 15 years & 9 & 6.3 \\
\hline & 16 to 20 years & 5 & 3.5 \\
\hline & More than 20 years & 7 & 4.9 \\
\hline
\end{tabular}

\section{Summary Statistics}

Descriptive analysis was conducted to summarize and describe all data that measures of the six independent variables proposed in the study. Table 6 tabulates the results consisting of ALL_TM (Top Management Commitment), ALL_IA (Internal Assessment), ALL_EP (Employee Participation), ALL_BL (Benchmarking Limitation), ALL_RQD (Role of Quality Department), ALL_CO (Customer Satisfaction) and ALL_EFF (Effectiveness of Library Benchmarking Adoption). The results show the followings. The overall means show moderately high agreement (approaching 4.0) which showing most of the respondents have tendency supportimg toward the library benchmarking adoption. Findings are also showing that all of the items' mean are all skewed towards high agreement, with means approaching 4.0 except ALL_BL (mean $=3.5$ ). The overall mean is 3.82 with s.d. $=0.5313$. It is clearly seen that all of the items' standard deviations are small, showing that majority of the responses converging towards agreement to the value of the means (less dispersion of opinions). 
INTERNATIONAL JOURNAL OF ACADEMIC RESEARCH IN BUSINESS AND SOCIAL SCIENCES Vol. 8, No. 9, Sept. 2018, E-ISSN: 2222-6990 @ 2018 HRMARS

Table 6: Summary statistics of the independent variables of the study

\begin{tabular}{|c|c|c|c|}
\hline Items & $\mathbf{N}$ & Mean & Std. Deviation \\
\hline ALL_TM & 142 & 3.96 & .59186 \\
\hline ALL_IA & 142 & 3.81 & .46408 \\
\hline ALL_EP & 142 & 3.92 & .49959 \\
\hline ALL_BL & 142 & 3.50 & .68655 \\
\hline ALL_RQD & 142 & 3.82 & .46879 \\
\hline ALL_CO & 142 & 3.94 & .47710 \\
\hline Overall & & 3.82 & 0.53133 \\
\hline
\end{tabular}

\section{Correlation}

Correlation analysis is a test where the relationship between variables will be established. In addition, correlation merely establishing the knowledge of bivariate relationships and not on cause and effect. The strength and magnitude of the relationships are measured by the correlation coefficient, ranging from $-1.0<\rho<+1.0$ (for population) or $-1.0<r<+1.0$ (for sample).

In justifying back the hypotheses generated for the study, Table 7 below exhibits the results on correlation between dependent and each of the independent variable. ALL_TM (Top Management Commitment), ALL_IA (Internal Assessment), ALL_EP (Employee Participation), ALL_BL (Benchmarking Limitation), ALL_RQD (Role of Quality Department) and ALL_CO (Customer Satisfaction) are all tested against ALL_EFF (Effectiveness of Library Benchmarking Adoption). Moderately strong positive correlation exists significantly between the effectiveness of library benchmarking adoption and employee participation. The same significant results is also exhibited by the correlation of dependent with the rests of the independents (but with only weak positive correlation) except benchmarking limitation which is not significant at $90 \%$ of significant level.

Table 7: Correlation results between ALL_EFF (dependent) and each independent variables

\begin{tabular}{|c|c|c|c|c|c|c|}
\hline & ALL_TM & ALL_IA & ALL_EP & ALL_BL & ALL_RQD & ALL_CO \\
\hline$r$ & $0.376^{* *}$ & $0.363^{* *}$ & $\mathbf{0 . 5 0 2}^{* *}$ & 0.057 & $0.300^{* *}$ & $0.336^{* *}$ \\
\hline$* 0, p<0.01$
\end{tabular}

\section{Summary of hypotheses test}

The correlation tests performed have shown some evidence with respect to bivariate relationships between the dependent and independent variables. Initial findings from correlation results are capable of providing useful insight on the hypothesized relationships. The summary of the findings are as given below: 
INTERNATIONAL JOURNAL OF ACADEMIC RESEARCH IN BUSINESS AND SOCIAL SCIENCES Vol. 8, No. 9, Sept. 2018, E-ISSN: 2222-6990 @ 2018 HRMARS

Table 8: Summary of hypothesis results

\begin{tabular}{|l|l|l|}
\hline & \multicolumn{1}{|c|}{ Hypothesis } & \multicolumn{1}{|c|}{ Result } \\
\hline H1 & $\begin{array}{l}\text { Benchmarking effectiveness is influenced by the top } \\
\text { management }\end{array}$ & Supported \\
\hline H2 & $\begin{array}{l}\text { Benchmarking effectiveness is influenced by the } \\
\text { internal assessment of the library }\end{array}$ & Supported \\
Benchmarking effectiveness is influenced by the & Supported \\
\hline H4 & $\begin{array}{l}\text { Benchmarking effectiveness is influenced by the } \\
\text { benchmarking limitation }\end{array}$ & $\begin{array}{l}\text { Not } \\
\text { Supported }\end{array}$ \\
\hline H5 & $\begin{array}{l}\text { Benchmarking effectiveness is influenced by the } \\
\text { role of the quality department }\end{array}$ & Supported \\
\hline H6 & $\begin{array}{l}\text { Benchmarking effectiveness is influenced by the } \\
\text { customer orientation of the library }\end{array}$ & Supported \\
\hline
\end{tabular}

\section{Discussion}

The research aims to examine the relationships between six posited library benchmarking elements with its effectiveness of library benchmarking adoption among academic libraries of public universities in Klang Valley, Malaysia. The elements are top management commitment, internal assessment, employee participation, benchmarking limitation, role of quality department and customer satisfaction. A correlational study was performed on the survey data among randomized selected academic librarians. Findings have shown evidence of significant correlation between dependent and independent variables except one element i.e. benchmarking limitation. Early insight drawn from the finding is that academic librarian have tendency to agreeable on the effectiveness of library benchmarking adopted in their varsities. Be it from the top management to employees, they are supportive to the initiative of benchmarking held at their academic libraries.

Significant positive relationships shown by the five elements witnessed the strongest correlation being between the effectiveness of library benchmarking adoption and employee participation with $r=0.502$. This shows that library staff are giving their support in achieving effective benchmarking and are as well giving their commitment toward improving the quality of library services. In terms of top management commitment, the correlation $r=0.376$ may imply to their influence or authority in orchestrating or supporting the library benchmarking adoption. Nevertheless, to what extent the commitment is beyond the scope of this study. Early insight that can be drawn their dedication to quality improvement cannot be doubted that might have positive impact in their library moving forward plans.

Correlation between effectiveness of library benchmarking adoption and internal assessment indicates weak positive relationship, with $r=0.363$. This results exhibits the existence of such relationships but it is weak though. Internal assessment can be considered as one approach to identify the openness of employee towards changes / improvement in the library, as well as to make ensure the participation of the employee in the benchmarking adoption. From the internal assessment, it leads to a better understanding on the operations / services that require improvement. 
INTERNATIONAL JOURNAL OF ACADEMIC RESEARCH IN BUSINESS AND SOCIAL SCIENCES Vol. 8, No. 9, Sept. 2018, E-ISSN: 2222-6990 @ 2018 HRMARS

Moreover, it allows awareness of learning portfolio in the library of it components and to get better understanding of its portfolio. Culture difficulties may be treated as one of the internal assessment elements due to reason that most of the employees have been working at the library for more than 5 years quite a long time and commonly have their own working culture.

The study also shows that quality department of a library has a significant relationship with effectiveness of library benchmarking adoption $(r=0.30)$. The main reason of the positively correlated relationship is the department would have an ability to access to top management and autonomy to run an project where they can have direct contact with top management who is highly anchored for decision making. Moreover, quality department also can fully utilize professional staff and thus is likely to grab the opportunity to improve the effectiveness of improving the quality of the library. In addition, quality department can assist to inspire awareness among staff with regards to achieving the effectiveness of library benchmarking adoption.

The element of customer satisfaction also exhibits positive correlation with effectiveness for library benchmarking adoption but with weak relationship, $r=0.336$. Customer satisfaction can be considered as one of the valuable impact for the benchmarking adoption as customer experience would be embraced through their journey in the adoption process, whether it would be successful or not. Therefore, the customer satisfactory must be prioritized first prior to comparing customer satisfaction with the competitors.

Other than that, library staff also must think of strategies that will achieve the customer orientation. In addition, librarian should utilizing customer satisfaction as part of the performance indicator from their job and increase their responsiveness from customers regarding their complaints or enquiry.

However, insignificant relationship is found between effectiveness for library benchmarking adoption and benchmarking limitation. It could be due to reason that items asked in the questionnaire benchmarking is too costly, too time consuming and difficult to identify benchmarking partners may not be non-critical or trivia with respect to the benchmarking process. For example, difficulties to obtain partners regarding benchmarking process may be catered or solved among higher level management prior to the benchmarking exercise taken place.

\section{Conclusion}

A study to examine the elements impacting the effectiveness for library benchmarking adoption of academic library is presented in the paper. The findings discussed indicate that the academic libraries in majority prone towards agreement on adopting the benchmarking so that the quality of library can be further improved from time to time. Moreover, user experience plays important point to be tracked so that library services/products can meet with their requirements. Besides challenges foreseen ahead, academic library should be ready and prepare their quality improvement road map so that the benchmarking process can be implemented as planned.

\section{References}

Adebanjo, D., Abbas, A., \& Mann, R. (2010). An investigation of the adoption and implementation of benchmarking. International Journal of Operations \& Production Management, 30(11), 11401169. doi:10.1108/01443571011087369 
INTERNATIONAL JOURNAL OF ACADEMIC RESEARCH IN BUSINESS AND SOCIAL SCIENCES

Vol. 8, No. 9, Sept. 2018, E-ISSN: 2222-6990 @ 2018 HRMARS

Adewunmi, Y. A., Koleoso, H., \& Omirin, M. (2016). A qualitative investigation of benchmarking barriers in Nigeria. Benchmarking: An International Journal,23(7), 1677-1696. doi:10.1108/bij-06-2014-0055

Balagué, N., \& Saarti, J. (2009). Benchmarking quality systems in two European academic libraries. Library Management, 30(4/5), 227-239. doi:10.1108/01435120910957896

Carpinetti, L. C., \& De Melo, A. M. (2002). What to benchmark? Benchmarking: An International Journal, 9(3), 244-255. doi:10.1108/14635770210429009

Castro, V. F., \& Frazzon, E. M. (2017). Benchmarking of best practices: an overview of the academic literature. Benchmarking: An International Journal, 24(3), 750-774. doi:10.1108/bij-03-20160031

Camp, R.C. (1989), Benchmarking -The Search for Industry Best Practices that Lead to Superior Performance.

Camp, R.C. (1992), "Learning from the best leads to superior performance", Journal of Business Strategy, Vol. 13 No. 3, pp. 3-6.

Camp, R.C. (1995), Business Process Benchmarking: Finding and Implementing Best Practices, ASQC Quality Press, Milwaukee, WI.

Dale, B.G., Sheppard, L. and Armitage, H. (1995), "The setting up and development of the Trafford Park performance and quality forum", The TQM Magazine, Vol. 7 No. 5, pp. 32-7.

Davis, P. (1998), "The burgeoning of benchmarking in British local government", Benchmarking for Quality Management \& Technology, Vol. 5 No. 4, pp. 26070.

Favret, L. (2000). Benchmarking, annual library plans and best value: the implications for public libraries. Library Management, 21(7), 340-348. doi:10.1108/01435120010338766

Freytag, P. V., \& Hollensen, S. (2001). The process of benchmarking, benchlearning and benchaction. The TQM Magazine, 13(1), 25-34. doi:10.1108/09544780110360624

Harris, S. (2017). 2016 top trends and issues in Jamaican academic libraries. Information and Learning Science, 118(1/2), 17-47. doi:10.1108/ils-10-2016-0069

Hart, S., \& Amos, H. (2014). The development of performance measures through an activity based benchmarking project across an international network of academic libraries. Performance Measurement and Metrics, 15(1/2), 58-66. doi:10.1108/pmm-03-2014-0010

Jackson, N. (2001), "Benchmarking in UK HE: an overview", Quality Assurance in Education, Vol. 9 No. 4, pp. 218-35.

Laeven, H., \& Smit, A. (2003). A project to benchmark university libraries in The Netherlands. Library Management, 24(6/7), 291-304. doi:10.1108/01435120310486002

Maire, J., Bronet, V., \& Pillet, M. (2005). A typology of "best practices" for a benchmarking process. Benchmarking: An International Journal, 12(1), 45-60. doi:10.1108/14635770510582907

Pin Lee, Y. (2004). Determinant of benchmarking adoption.

Podsakoff, P. M., MacKenzie, S. B., Lee, J.-Y., \& Podsakoff, N. P. (2003). Common method biases in behavioral research: A critical review of the literature and recommended remedies. Journal of Applied Psychology, 88(5), 879-903. doi: 10.1037/0021-9010.88.5.879.

Podsakoff, P. M., MacKenzie, S. B., \& Podsakoff, N. P. (2012). Sources of Method Bias in Social Science Research and Recommendations on How to Control It. Annual Review of Psychology, 63(1), 539-569. doi: doi:10.1146/annurev-psych-120710-100452 
INTERNATIONAL JOURNAL OF ACADEMIC RESEARCH IN BUSINESS AND SOCIAL SCIENCES

Vol. 8, No. 9, Sept. 2018, E-ISSN: 2222-6990 @ 2018 HRMARS

Pin Lee, Y., Zailani, S., \& Lin Soh, K. (2006). Understanding factors for benchmarking adoption. Benchmarking: An International Journal, 13(5), 548-565. doi:10.1108/14635770610690401

Saunders, M., Mann, R., \& Smith, R. (2007). Benchmarking strategy deployment practices. Benchmarking: An International Journal, 14(5), 609-623. doi:10.1108/14635770710819281

Sik-wah Fong, P., Shen, Q., \& Cheng, E. W. (2001). A framework for benchmarking the value management process. Benchmarking: An International Journal, 8(4), 306-316. doi:10.1108/14635770110403800

Simon, C. (2011). An examination of best practices and benchmarking in corporate libraries. Journal of Management Development, 30(1), 134-141. doi:10.1108/02621711111098433

Tasopoulou, K., \& Tsiotras, G. (2017). Benchmarking towards excellence in higher education. Benchmarking: An International Journal, 24(3), 617-634. doi:10.1108/bij-032016-0036

Tee, K. F. (2016). Suitability of performance indicators and benchmarking practices in UK universities. Benchmarking: An International Journal, 23(3), 584-600. doi:10.1108/bij-072014-0069

Van der Wiele, T., Dale, B., \& Williams, R. (2000). Business improvement through quality management $\quad$ systems. Management $\quad$ Decision, 38(1), 19-23. doi:10.1108/00251740010311799

Watson, G.H. (1993), Strategic Benchmarking: How to Rate your Company's Performance Against the World's Best.

Zairi, M. \& Ahmed, P.Z. (1999), "Benchmarking maturity as we approach the millennium?", Total Quality Management, No. 4/5, July, pp. 810-16.

Zeinalnezhad, M., Mukhtar, M., \& Sahran, S. (2014). An investigation of lead benchmarking implementation. Benchmarking: An International Journal, 21(1), 121-145.doi:10.1108/bij09-2011-0074 